\title{
The green potential of occupations in Switzerland
}

\author{
Michael Lobsiger ${ }^{1 *}$ (D) and Christian Rutzer ${ }^{2}$
}

\begin{abstract}
We use a data-driven methodology to quantify the importance of different skills in performing green tasks, aiming to estimate the green potential of occupations in Switzerland. By this we mean the potential of an occupation to be able to perform green tasks on the basis of the skills attributed to it, whereby it is irrelevant whether the occupation already bundles green tasks or not. The results show that occupations with a high green potential are predominantly those with an engineering and technical background. In order to substantiate our green potential measure, we provide evidence of a positive association between demand of employment in occupations with high green potential and an increase in the implicit tax rate on greenhouse gas emissions. The share of employment in occupations with a green potential above a reasonable threshold in the total Swiss labour force is 16.7\% (number of persons employed) and $18.8 \%$ (full-time equivalents). These employed persons are, on average, younger, more often men, have a higher level of educational attainment and a higher probability of having immigrated than employed persons in occupations with low green potential.
\end{abstract}

Keywords: Green potential, Green transition, Labour market

JEL Classification: J23, J24, Q52

\section{Introduction}

Environmental awareness has increased in the population in recent years, especially against the background of climate change. These developments have also led to regulatory activities at the political level. ${ }^{1}$ Strategies and action plans are aimed, among other things, at increasing the resource efficiency of production and achieving a more sustainable economy. ${ }^{2}$ As recognized by research

\footnotetext{
${ }^{1}$ Based on country case studies Strietska-Ilina et al. (2011) identify other drivers of greening economies such as changes in the physical environment, technological development, developments of markets for green products and services, and changing consumer habits.

${ }^{2}$ In this paper, green economy and sustainable economy are used as synonyms. Footnote 6 provides a definition of the concept green economy. For Switzerland, the Federal Councils Sustainable Development Strategy 20162019 (Bundesrat, 2016) can be mentioned in this context. The strategy sets out a number of objectives, one of which aims at improving resource effi-
}

*Correspondence: michael.lobsiger@bss-basel.ch

1 BSS Economic Consultants, Aeschengraben 9, 4051 Basel, Switzerland Full list of author information is available at the end of the article and practice alike, such a transformation towards a more sustainable economy may also have strong effects on the labour market (e.g. Vona et al., 2018). Specifically, the labour market asks for employees with specific skills (knowledge, abilities, skills in the narrower sense and attitudes) that are necessary to perform green tasksthat is work activities that make a positive contribution to the green economy. These tasks will be increasingly demanded on the path to a more sustainable economy (Rutzer et al., 2020; Janser, 2018).

Against this background, it is important to know which Swiss occupations have a high potential to perform green tasks. By this we mean the potential of an occupation to be able to perform green tasks on the basis of the skills attributed to it, whereby it is irrelevant whether the occupation already bundles green tasks or not (Rutzer

Footnote 2 (Continued)

ciency in production. Specific measures to achieve better resource efficiency are set out in the 2013 Green Economy Action Plan and its development for the period 2016-2019 (BAFU, 2013, 2016). 
et al., 2020). An electrical engineer, for example, can put her skills to work both overseeing a nuclear reactor at a nuclear power plant or researching renewable energy. Only in the second case does she perform a green task, but in any case she brings the potential to perform green tasks. Therefore, information about the green potential of occupations seems central to us, e.g. for education and training policy: The need to align education and training with green transformation will be less urgent if many workers are employed in occupations with high green potential. This is because one can assume that, to a certain extent, they have the necessary skills to carry out green tasks and are thus well prepared for a green transformation.

In order to quantify the green potential of occupations in Switzerland, we follow a novel approach developed by Rutzer et al. (2020). The approach relies on machine-learning algorithms to quantify the importance of different skills in performing green tasks. The results show that occupations with a high green potential are predominantly those with an engineering and technical background. Once the green potential of different Swiss occupations is determined, we aim at finding empirical support for our measure of the green potential of occupations. In particular, we follow a recent strand of the literature examining heterogeneous demand responses in labour markets (measured at the occupational level) with respect to changes in environmental policy stringency (Niggli \& Rutzer, 2020; Vona et al., 2018). In particular, we investigate whether occupations with high green potential are in higher demand relative to other occupations when environmental policy stringency proxied by green emission taxes increases. The results provide evidence of a positive association between demand of occupations with high green potential and an increase in the implicit emission tax. Although we do not claim a causal relationship, we interpret this result as empirical support for the estimated green potential of occupations in Switzerland.

Next, we use our green potential estimates at the occupational level to determine the proportion of employees in Switzerland working in occupations considered to have a high green potential. Furthermore, we describe their socio-economic background. In particular, we characterize employment in occupations with high green potential along different dimensions such as age, sex, migration status and level of education as well as a set of labour market indicators (rate of job vacancies, rate of unemployment). For that, we divide the occupations into two groups based on a particular threshold for the green potential (which we will justify later). According to our estimates, in Switzerland in the year 2017, 739,000 persons and 670,000 full-time equivalents (FTE) have been employed in occupations with high green potential. Measured relative to the total number of persons employed and FTE, this is around $16.7 \%$ and $18.8 \%$, respectively. Employed persons in occupations with high green potential are, on average, younger, more often men, have a higher level of educational attainment and a higher probability of having immigrated than employed persons in other occupations. Moreover, the group of occupations with high green potential has a lower unemployment rate and a higher job vacancy rate.

The rest of the paper is structured as follows: Next, we review the literature (1) assessing the extent of greenness of occupations based on task level information, (2) relating the extent of greenness of occupations to skills and (3) analysing heterogeneous demand responses of the labour market due to green economy measures. Afterwards, we describe our methodology to estimate the green potential of occupations and the estimates thereof. We then outline our empirical strategy to analyse possible heterogeneous labour market effects in response to changes in environmental policy stringency and provide the respective estimation results. Consequently, we characterize employment in occupations with high green potential along different dimensions. Finally, we summarize our main findings and conclude.

\section{Literature}

Our paper can be attributed to the growing literature analysing the impact of a green economy on the labour market by applying a task-based approach. This approach is conceptually related to a rich literature that analyses how labour market outcomes (such as employment and wages) are shaped by skills and tasks (Acemoglu \& Autor, 2011). ${ }^{3}$ In particular, our approach to estimating the green potential of occupations is based on two strands of the literature:

First, there is the literature that assesses the extent of greenness of occupations based on task level information. Consoli et al. (2016) use occupation and task level information provided by $\mathrm{O}^{*} \mathrm{NET}^{4}$ to classify occupations as green or non-green in order to elaborate on the differences between both occupational groups in terms of skill content and human capital. As Bowen et al. (2018) point out, there is considerable heterogeneity among the occupations considered as green with respect to the

\footnotetext{
${ }^{3}$ According to Acemoglu and Autor (2011, p. 1045), “[...] a task is a unit of work activity that produces output (goods and services). In contrast, a skill is a worker's endowment of capabilities for performing various tasks. Workers apply their skill endowments to tasks in exchange for wages, and skills applied to tasks produce output."

4 The Occupational Information Network (O*NET) is a US American database that holds various job-related information. More information about O*NET will follow in Sect. 3.
} 
"greenness"- that is the use of green tasks within occupations. Again relying on O*NET, Vona et al. (2018) exploit this variation in the use of green tasks within occupations to compute a continuous greenness measure for each occupation. An alternative approach to measure the greenness of occupations based on tasks has been developed by Janser (2018). Based on job requirements stated in the German occupations database BERUFENET and applying a text mining approach, they identified green tasks in Germany. On this basis, they computed a greenness-of-jobs index per occupation by relating the identified green tasks (that is job requirements that contain key words form a pre-defined green tasks dictionary) to all job requirements. ${ }^{5}$ This approach is interesting because it shows a way to identify green tasks apart from using the O*NET database. It has the advantage that countryspecific occupational information databases can be used for task identification and do not require a diversion via O*NET. However, identifying green tasks is only one step towards estimating the green potential of occupations. In order to estimate the potential for all occupations (including those without green tasks), detailed occupation-specific information on skills is necessary.

This is where the second strand of the literature on which our approach is based comes in, namely the research relating the extent of greenness of occupations to skills. Vona et al. (2018) use the continuous greenness measure (see above) to assess the importance of green skills for the exercise of green tasks. Their analysis is based on O*NET that provides, apart from information about green tasks within occupations, detailed information about skills on the level of occupations. A recent approach by Rutzer et al. (2020) starts here and offers a method to estimate the green potential of occupations based on skills in a continuous way. Rutzer et al. (2020) define the green potential of an occupation based on the skills which are required to perform green tasks. It is not important whether an occupation bundles green tasks or not, but whether the skills needed to perform those work activities would in principle allow green tasks to be performed. Essentially, the idea is that a set of skills can be applied to different (green or non-green) tasks. In this respect, there are no green skills, but skills that are better suited than others to exercise green tasks. While following Vona et al. (2018) in terms measuring the greenness of occupations and using information of skills provided by O*NET, Rutzer et al. (2020) use a different estimation approach that delivers (from a statistical point of

\footnotetext{
${ }^{5}$ Janser (2018) differentiates between core and additional job requirements, the former being essential to the practice of the profession. In 2016, 190 job requirements (2.6\% of all job requirements) were green tasks. $19.9 \%$ of all occupations (according to the Klassifikation der Berufe 2010-KldB2010) contained at least one of these 190 green tasks.
}

view) more accurate predictions of the green potential of occupations. In particular, the method of Rutzer et al. (2020) relies on machine learning and not on a principal component analysis on the top of OLS estimations as Vona et al. (2018) do. The statistical superiority of the former method is probably mainly due to the fact that it also makes it possible to use information of skills that are highly needed for non-green tasks. In contrast, Vona et al. (2018) only exploits information from skills that are important for green tasks.

The concept of green potential contrasts strongly with current methods of identifying so-called green jobs and determining employment in these occupations on this basis. A uniform definition of green jobs is missing (Bowen et al., 2018; Janser, 2018; Esposito et al., 2017). The literature therefore provides different definitions based on industry affiliation or the production methods used (Martinez-Fernandez et al. 2010; Consoli et al., 2016; Bowen et al., 2018). A frequently used approach to identify green jobs starts at the industry level and identifies those sectors that produce goods and services that contribute to the protection of the environment or the conservation of natural resources. In particular, the efforts of statistical offices to define the so called Environmental Goods and Services Sector (EGSS) and describe it in terms of employment and value added are to be mentioned here (Eurostat, 2016; ILO, 2018). This approach has, however, some drawbacks: As noted in ILO (2018) and Esposito et al. (2017), it neglects jobs that improve production processes with respect to their environmental impact, irrespective of the goods that are produced. Furthermore, it does not shed light on the skills necessary to carry out an activity that is expected to contribute to a sustainable economy and therefore says nothing in terms of an occupation's potential to bundle green tasks. But precisely this information is of interest to education policy and practice in order to, for example, gear training courses to the needs of a sustainable economy.

While there are estimates of employment in green industries in Switzerland (according to the definition of the EGSS, covering employment in industries that produce goods and services contributing to the protection of the environment or the conservation of natural resources), there are no estimates based on the concept of green potential. Here we make a contribution by applying the approach of Rutzer et al. (2020) to determine the green potential of Swiss occupations. To the best of our knowledge, a database that allows both the identification of green tasks and provides information on skills at the occupational level is not available in Switzerland. For this reason, we will follow Rutzer et al. (2020) and rely our analysis on $\mathrm{O} * \mathrm{NET}$ data. 
Once the green potential of different occupations is determined, we aim to find empirical support for our measure of the green potential of occupations. For that, we follow a recent strand of the literature examining heterogeneous demand responses in labour markets (measured at the occupational level) with respect to changes in environmental policy stringency (Niggli \& Rutzer, 2020; Vona et al., 2018). The execution of occupations with high green potential requires skills that allow to perform green tasks. A central hypothesis is that these tasks and the skills associated with them will be in greater demand in case of a green shift of an economy (e.g. Vona et al., 2018). In such a case, one would accordingly expect a higher demand for occupations that require these tasks and skills compared to other occupations: On the one hand, occupations that already bundle green tasks benefit from the increased demand due to environmental policy becoming more stringent. On the other hand, occupations that do not yet bundle green tasks, but already require skills that are necessary to perform these tasks, are predestined to include green tasks in their activity bundle as a result of a development towards a green economy (Niggli \& Rutzer, 2020). Niggli and Rutzer (2020) provide a recent empirical contribution with respect to heterogeneous labour market effects on the occupational level. They estimate the green potential of occupations for 19 European countries following Rutzer et al. (2020). On this basis, they then analyse the effect of increased environmental policy stringency on the occupation-level manufacturing employment for the period 1992 to 2010. In line with other literature (Vona et al., 2018; Marin \& Vona, 2019), they provide evidence for heterogeneous employment changes in response to an increase in environmental policy stringency. In particular, they document a decrease in labour demand for occupations with relatively low green potential and an increase in labour demand for occupations with relatively high green potential. We add to this literature by providing further evidence of heterogeneous labour demand responses associated with increased greenhouse gas emission taxes as a proxy for environmental policy stringency, using Switzerland as an example.

After this brief review of the literature, the next section deals with the methodological approach and the data we use to estimate the green potential of occupations in Switzerland.

\section{Quantifying and testing the green potential of occupations}

In the following, we first provide detailed information about the measurement of the green potential of occupations in Switzerland and the respective results. Afterwards, we inform about the methodological approach to analyse heterogeneous labour market effects to green economy measures and describe the data needed for this analysis. Finally, we provide the respective results.

\subsection{Measurement of the green potential of occupations}

The measurement of the green potential of occupations in Switzerland draws on the recent contribution of Rutzer et al. (2020). This work estimates the green potential of occupations in the US labour market, that is, for occupations classified according to the Standard Occupational Classification (SOC). This approach can be adapted so it can be used to estimate the green potential of occupations in Switzerland (and other countries) relying on a different classification system for occupations, namely the International Standard Classification of Occupations (ISCO). The following section briefly discusses this approach and highlights the modifications that need to be made to apply it to Swiss data. Here we follow the approach of Niggli and Rutzer (2020) and refer to this article for a detailed description of the procedure.

The estimates of Rutzer et al. (2020) of the green potential for SOC occupations are based on data from O*NET. This database provides information about the tasks and skills contained in occupations and classifies tasks as green or non-green. The classification of tasks according to green or non-green is carried out by experts. A green task is a work activity that makes a positive contribution to the green economy ${ }^{6}$ (e.g. the development of a method for measuring water quality).

Table 1 provides four examples of different O*NET occupations. For the solar photovoltaic installer, O*NET lists a total of 26 tasks, where 26 tasks are classified as "green new tasks". The environmental engineer bundles a total of 28 tasks, three of which are green new tasks and 25 that are existing green tasks. An example of an "existing green task" is designing or supervising of the design of systems, processes, or equipment for control, management, or remediation of water, air, or soil quality. An example of a "new green task" is writing reports or articles for Web sites or newsletters related to environmental engineering issues. Architects have seven new green tasks and 18

\footnotetext{
${ }^{6}$ According to Dierdorff et al. (2009, p. 3), "[t] he green economy encompasses the economic activity related to reducing the use of fossil fuels, decreasing pollution and greenhouse gas emissions, increasing the efficiency of energy usage, recycling materials, and developing and adopting renewable sources of energy."
} 
Table 1 Examples of green jobs and tasks according to O*NET

\begin{tabular}{lllll}
\hline Title & \multicolumn{2}{l}{ \# of tasks } & & Other \\
\cline { 2 - 4 } & Green & Existing & Greenness $\eta$ \\
\cline { 2 - 4 } & New & 26 & 0 & 1.0 \\
\hline Solar photovoltaic installer (47-2231.00) & 3 & 25 & 0 & 1.0 \\
Environmental engineer (17-2081.00) & 7 & 0 & 18 & 0.3 \\
Architect (17-1011.00) & 0 & 0 & 21 & 0.0 \\
Electrician (47-2111.00) & & 0 & 0 \\
\hline
\end{tabular}

Source: O*NET

non-green tasks. Designing or constructing plans of green buildings projects to minimize adverse environmental impact or conserve energy is an example of a "new green task". Tasks such as preparing scale drawings or architectural designs, using computer-aided design or other tools that has no obvious impact on the green economy are examples of "non-green tasks". 21 tasks can be attributed to the electrician occupation, none of which are considered green.

On that basis Rutzer et al. (2020) calculate the greenness of an occupation $i$ as $\eta_{i}=\#$ green tasks $s_{i}$ \#total tasks t $_{i}$. In the examples provided by Table 1 (last column), two occupations have a $\eta=1.0$ (solar photovoltaic installer, environmental engineer), one a $\eta=0.3$ (architect) and one a $\eta=0$ (electrician). It is important to note that there are occupations that do not perform any green tasks, that is jobs with $\eta=0$, but demand skills similar to occupations that perform green tasks. While these occupations do not bundle green tasks, they nevertheless have the potential to perform green tasks based on the skills required. The calculation of this potential is what is at the heart of the measurement strategy used in this analysis. For example, it is not a-priori clear that electricians that perform, according to the O*NET classification, no green tasks (cf. Table 1) have a low green potential. Indeed, as the calculations later will show, electricians are assigned to an occupational group that has a relatively high green potential, because it is associated with skills that are similar to occupations that perform green tasks. In other words, employees that work as electricians are thought to

\footnotetext{
${ }^{7}$ It is important to note that there is no uniform definition of skills in the literature (OECD, 2017). We stick to the definition used by O*NET as we will base our analyses strongly on this database. For detailed information on the database, see https://www.onetcenter.org/database.html\#individual-files. The following definitions were taken from https://www.onetcenter.org/reports/ Related.html (Volume I: Report): Knowledge is defined as a "[...] collection of discrete but related and original facts, information, and principles about a certain domain that is acquired through education, training, or experience" (such as "Administration and Management" or "Design"), skills (basic and cross-functional) is defined as "[...] capabilities of individuals that are acquired through experience and practice, and are used to facilitate knowledge acquisition" (such as "Mathematics" or "Writing"), work activities is defined as an "[...] aggregation of similar job activities/behaviors that underlie the accom-
}

be equipped with skills that are a prerequisite to perform green tasks.

Besides information about tasks, O*NET provides detailed information about job-specific skills for every occupation. Following Vona et al. (2018), skills are understood as knowledge, skills (in the narrower sense) and work activities. ${ }^{7} \mathrm{O}^{*} \mathrm{NET}$ provides, for each occupation, a quantitative rating for the importance (IM) and the level $(L V)$ of a total of 114 skills. For each skill $s$, this information is aggregated into a single value by applying a weighting scheme of importance and level. Following Rutzer et al. (2020), the value of a skill $s$ of occupation $i$ is calculated as $\operatorname{skill}_{i, s}=\mathrm{IM}_{i, s}^{\alpha} \mathrm{LV}_{i, s}^{1-\alpha}$ with $\alpha=0.7$. Afterwards, the value of each skill $i, s$ is normalized between 0 and 1 by computing $\left(\operatorname{skill}_{i, s}-\min \left(\operatorname{skill}_{s}\right)\right) /\left(\max \left(\operatorname{skill}_{s}\right)-\min \left(\operatorname{skill}_{s}\right)\right)$.

Using machine-learning algorithms, it is possible to predict the potential of SOC occupations to perform green tasks on a continuous scale. For that, a prediction model is trained to predict the greenness of an occupation depending on the values of different skills using data from $\mathrm{O}^{*} \mathrm{NET}$. According to the analysis of Rutzer et al. (2020), the Ridge algorithm performs best compared to alternative estimation models (OLS, Lasso, Random forest) in terms of prediction quality (measured by the mean squared error and the multiclass receiver operating characteristic curve (Mroc) on a holdout dataset). ${ }^{8}$ For this reason, the estimation of the green potential for SOC occupations is based on the Ridge regression model. The model uses the information on skills described above as explanatory variables and the greenness $\eta_{i}$ of an occupation $i$, that is the share of green tasks within the total number of tasks, as the dependent variable. The result is a coefficient $\hat{\beta}_{s}^{\text {ridge }}$ for each skill $s$, which can be used to predict the green potential $\hat{\eta}_{i}$ of an occupation $i$ :

\footnotetext{
Footnote 7 (Continued)

plishment of major work functions" (such as "Analyzing Data or Information" or "Developing and Building Teams").

${ }^{8}$ In comparison to OLS, the Ridge regression endogenously shrinks some coefficients towards zero in order to reduce overfitting to the training data.
} 


$$
\hat{\eta}_{i}=\hat{\beta}_{0}+\sum_{s=1}^{p} \operatorname{skill}_{i, s} \hat{\beta}_{s}^{\text {ridge }} .
$$

Table 6 in the "Appendix 1" shows, for each considered skill $s$, the coefficient $\hat{\beta}_{s}^{\text {ridge }}$. On the one side, there are skills associated with a high predicted greenness as "Building and Construction", "Geography" and "Physics" with coefficients of 0.15 and 0.08 , respectively. On the other side are skills such as "Support", "Fine Arts" and "Foreign Language" that are associated with a low predicted greenness carrying the coefficients of -0.13 , -0.09 and -0.08 , respectively. When interpreting the coefficients, however, it is important to note that they are not unbiased, since the Ridge regression shrinks coefficients of skills with low prediction power towards zero.

O*NET provides information on the value of a skill $s$ of occupation $i$ (skilli,s) according to the SOC on an 8-digit level. In order to estimate the green potential for occupations according to the ISCO 08 on the 3-digit level based on Eq. (1), the values of the skills must accordingly be transferred. Here we follow Niggli and Rutzer (2020) (and the work cited therein) and carry out the following three steps:

1. The values of a particular skill $s$ of all occupations $i$ belonging to the same 6-digit SOC occupation are transferred to that 6-digit level SOC occupation by taking a simple (unweighted) average.

2. The skill $i_{i, s}$ is then transferred to ISCO occupations, where a conversion table (provided by the US Bureau of Labor Statistics (BLS)) informs about the relations between SOC occupations on the 6-digit level and ISCO occupations on the 4-digit level. In the case of multiple matches, a simple (unweighted) average is used. The transfer of job information prepared for the US labour market to the European context in this second step can be seen as a limitation of this approach. However, following research of other scientists (e.g. OECD, 2017), we assume that this transfer is by and large permissible. Firstly, environmental issues arise not only in Switzerland, but internationally. Secondly, we assume that a skilled worker in both the USA and Switzerland must, with a few exceptions (e.g. in terms of nomenclature), has the same skills in order to be able to carry out the tasks assigned to her. For example, electricians must have the skills to estimate the necessary material quantities on the basis of planning documents and to install switches and sockets, no matter where they work.

3. The skill $i, s$ for ISCO occupations on the 3-digit level are computed by taking simple (unweighted) averages of all values of a particular skill $s$ of all 4-digit occupations that belong to a 3-digit occupation.
On that basis, it is then possible to apply the trained model (see Eq. 1) to predict the potential of 3-digit ISCO occupations to perform green tasks. Finally, we normalize the green potential of occupations on a scale between 0 and 1 , whereby the value of $1(0)$ is attributed to the occupation with the highest (lowest) estimated green potential. The values for the other occupations $i$ are then calculated relative to the values of the occupations with the highest and lowest green potential: $\left(\hat{\eta}_{i}-\min (\hat{\eta})\right) /(\max (\hat{\eta})-\min (\hat{\eta}))$.

A summary of the results is shown in Table 2. It lists the ten occupations with the highest green potential estimates. As one can see, Engineering professionals have the highest green potential with a value of 1 , followed by Physical and earth science professionals with a value of 0.76 and Production managers in agriculture, forestry and fisheries with a value of 0.76 . The green potential of all occupations used in this study are shown in Table 7 in the "Appendix".

\subsection{Emission tax, green potential and employment}

In the previous section, we determined the green potential of ISCO occupations. In doing so, we argued that such occupations have skills needed to perform green tasks. Therefore, in case of a green shift of an economy one would expect a relatively high demand for such jobs compared to jobs that do not have such skills. In the following, we would like to examine whether we find signs of such a heterogeneous demand response in the Swiss labour market. Specifically, we use changes in the implicit tax rate on greenhouse gas emissions at a two-digit industry level to investigate whether this is associated with a heterogeneous change in the demand for workers with higher green potential relative to those with lower green potential. For this purpose, we estimate the following empirical model

$$
\log \mathrm{emp}_{i, j, t}=\beta_{1} \hat{\eta}_{i} \tau_{j, t}+\boldsymbol{\gamma} \mathbf{X}_{j, t}+\delta_{t}+\epsilon_{i}+v_{j}+u_{i, j, t},
$$

where our left-hand side variable $\log \mathrm{emp}_{i, j, t}$ consists of the $\log$ of employment of occupation $i$ in industry $j$ at time $t, \tau_{j, t}$ stands for the implicit emission tax of industry $j$ at time $t$. We interact the implicit emission tax with our previous determined green potential level $\hat{\eta}_{i}$ of an occupation $i$ in order to analyse possible heterogeneous labour market responses. In addition, the matrix $\mathbf{X}_{j, t}$ contains control variables, such as the non-interacted implicit emission tax $\tau_{j, t}$ and the labour productivity at the industry level. In addition, we use time fixed effects $\left(\delta_{t}\right)$, occupational fixed effects $\left(\epsilon_{i}\right)$ and industry fixed effects $\left(v_{j}\right) .{ }^{9}$ For example, the fixed effects take into

\footnotetext{
${ }^{9}$ Our specification does not include a term $\hat{\beta}_{3} \hat{\eta}_{i}$, because it is completely captured by the occupational fixed effect $\epsilon_{i}$.
} 
Table 2 Occupations with highest green potential

\begin{tabular}{lll}
\hline ISCO & Occupation & Green potential \\
\hline 214 & Engineering professionals (excluding electrotechnology) & 1.00 \\
211 & Physical and earth science professionals & 0.76 \\
131 & Production managers in agriculture, forestry and fisheries & 0.76 \\
210 & Science and engineering professionals, nos & 0.75 \\
312 & Mining, manufacturing and construction supervisors & 0.75 \\
215 & Electrotechnology engineers & 0.73 \\
132 & Manufacturing, mining, construction, and distribution managers & 0.72 \\
216 & Architects, planners, surveyors and designers & 0.71 \\
112 & Managing directors and chief executives & 0.68 \\
314 & Life science technicians and related associate professionals & 0.68 \\
$\ldots$ & $\ldots$ & $\ldots$ \\
\hline
\end{tabular}

Own calculations based on Rutzer et al. (2020)

account unobserved heterogeneity among different ISCO occupations that may affect the level of employment and industry-specific employment differences. Finally, $u_{i, j, t}$ is the error term.

To summarize, our estimation strategy relies on analysing variations in the number of employed persons over time within industry-specific occupational groups that differ according to their green potential. It is important to note that our specification only shows an association and not a causal relationship. Since the aim of this analysis is to empirically support our measure of the green potential of occupations, we consider establishing a controlled correlation as sufficient.

\subsection{Data}

Next, we provide an overview of the data used to estimate equation (2). Our analysis is based on different data sources: Firstly, we use data from the O*NET database (v21.2). We have already described it in Chapter 3.1 when discussing the measurement of the green potential of occupations. Secondly, for the number of employed persons we use data from the Swiss Labour Force Survey (SLFS) for the years 2008-2017. The SLFS provides information on the structure of the labour force and employment behaviour patterns. Specifically, in addition to general socio-economic information, the SLFS contains information on the job currently exercised, according to the ISCO nomenclature and the industry where the person is employed, which corresponds to the six digit NOGA-2008 nomenclature. ${ }^{10}$ Thirdly, we use data on expenditures on greenhouse gas emissions (measured in millions of Swiss Francs) and greenhouse gas emissions (measured in thousand tons of $\mathrm{CO}_{2}$ equivalent emissions) from the Federal Statistical Office (FSO).

\footnotetext{
${ }^{10}$ The NOGA nomenclature is identical to the NACE classification up to a four-digit level.
}

This information is available at the two digit NOGA-2008 industry level-and for some industries for a grouping of several two digit industries-from 2008 onwards and allows us, for each industry and year, to calculate an implicit tax rate by dividing the environmental expenditures through the greenhouse gas emissions. Afterwards, we multiply the result by 1000 to get an implicit emission tax measured as Swiss Franc per one ton of $\mathrm{CO}_{2}$ equivalent emission. A list of industries and their corresponding change in the implicit emission tax between our first year 2008 and last year 2017 can be found in the "Appendix 3". In total, we have data for 37 different industries of the second (manufacturing) and third sector (services). Fourthly, we use data from the FSO to calculate the labour productivity at the industry level (value added at the industry level divided by the number of employment). Having outlined the data, we now turn to the empirical results.

\subsection{Empirical results}

Table 3 shows the main results. The first row captures whether there exists an heterogeneous association between implicit emission tax and labour demand.

The variable is highly significant with a positive sign in all of our four specifications either above or almost at the $99 \%$ level. In particular, the first column shows our baseline specification. This specification controls only for general economic conditions and time-invariant occupation- and industry specific effects, such as the routine intensity of occupations. Therefore, we add yearindustry fixed effects and, additionally, year-occupation fixed effects to capture time varying effects at the most disaggregated level. As one can see in columns (2) and (3), the coefficient remains very stable. Note that, in this case, the implicit emission tax without interaction is completely absorbed by the fixed effects. In a last step, 
Table 3 Association between Implicit Emission Tax and Employment

\begin{tabular}{|c|c|c|c|c|}
\hline & \multicolumn{4}{|c|}{ Dependent variable } \\
\hline & \multicolumn{4}{|c|}{$\log \left(\right.$ employment $\left.{ }_{i, j,}\right)$} \\
\hline & $(1)$ & $(2)$ & (3) & (4) \\
\hline Implicit emission $\operatorname{tax}_{j, t} \times$ & $0.0626^{* *}$ & $0.0649^{* * *}$ & $0.0655^{* * *}$ & $0.0573^{* *}$ \\
\hline Green potential $\hat{\eta}_{i}$ & $(0.0245)$ & $(0.0247)$ & $(0.0251)$ & $(0.0240)$ \\
\hline Implicit emission tax $j, t$ & $\checkmark$ & & & $\checkmark$ \\
\hline Occupation fixed effects & $\checkmark$ & $\checkmark$ & $\checkmark$ & \\
\hline Industry fixed effects & $\checkmark$ & $\checkmark$ & $\checkmark$ & $\checkmark$ \\
\hline Year dummies & $\checkmark$ & $\checkmark$ & $\checkmark$ & $\checkmark$ \\
\hline Year-industry fixed effects & & $\checkmark$ & $\checkmark$ & \\
\hline Year-occupation fixed effects & & & $\checkmark$ & \\
\hline log(labour productivity) & & & & $\checkmark$ \\
\hline 3-digit ISCO time trends & & & & $\checkmark$ \\
\hline Observations & 22,642 & 22,642 & 22,642 & 22,642 \\
\hline Pseudo- $R^{2}$ & 0.0691 & 0.0698 & 0.0422 & 0.0695 \\
\hline
\end{tabular}

The sample is an unbalanced panel covering 37 Swiss industries between 2008 and 2017. The dependent variable in all columns is the log of occupational employment. All model specifications include fixed effects for industries and years. Columns (1), (2) and (3) further include occupation fixed effects. Columns (1) and (4) additionally include the implicit emission tax. Columns (2) and (3) additionally contain yearly occupation and industry fixed effects. Furthermore, column (4) contains the labour productivity at the industry level in logarithmic form and occupation time trends. Data are from the FSO and the SLFS. Standard errors in parentheses are clustered at the industry level. Significance levels for the coefficients are indicated as: ${ }^{*} p<0.1$; $^{* *} p<0.05$; $^{* *} p<0.01$

we use the labour productivity at the industry level and 3-digit ISCO time trends to control for major structural changes such as digitization and the increasing globalization. Again, the coefficient of our variable of interest remains almost the same (column 4). Moreover, in order to check the robustness of our results, we varied the time period, excluded the most and least polluting industries and also the most and least affected ISCO occupations. The results can be found in "Appendix 4" and generally confirm the heterogeneous association demonstrated in Table 3.

So far, the estimates are based on a continuum of green potential. However, for our subsequent descriptive characterization of employment in occupations with high green potential, it is necessary to divide occupations into discrete groups. For this purpose, we divide the ISCO occupations into two groups based on their green potential. In particular, we classify all ISCO occupations with a green potential larger or equal to 0.5 as occupations with high green potential and the rest as occupations with low green potential. The choice of the threshold is further
Table 4 Association between Implicit Emission Tax and Employment: Binary case

\begin{tabular}{|c|c|c|c|c|}
\hline & \multicolumn{4}{|c|}{ Dependent variable: } \\
\hline & \multicolumn{4}{|c|}{ 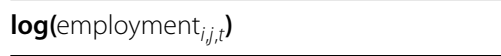 } \\
\hline & (1) & (2) & (3) & (4) \\
\hline Subset of green potential: & Full sample & $<0.5$ & $\geq 0.5$ & Full sample \\
\hline $\begin{array}{l}\text { Implicit emission } \operatorname{tax}_{j, t} \times \\
\nVdash_{\eta \geq 0.5}\end{array}$ & $\begin{array}{l}0.0381^{* * *} \\
(0.0147)\end{array}$ & & & \\
\hline $\begin{array}{l}\text { Implicit emission } \operatorname{tax}_{j, t} \times \\
\nVdash_{\eta<0.5}\end{array}$ & $\begin{array}{l}0.0071 \\
(0.0106)\end{array}$ & & & \\
\hline Implicit emission $\operatorname{tax}_{j, t} \times$ & & 0.0368 & 0.00402 & $0.0626^{* *}$ \\
\hline Green potential $\hat{\eta}_{i}$ & & $(0.0407)$ & $(0.0350)$ & $(0.0245)$ \\
\hline Implicit emission tax $x_{j, t}$ & & $\checkmark$ & $\checkmark$ & $\checkmark$ \\
\hline Occupation fixed effects & $\checkmark$ & $\checkmark$ & $\checkmark$ & $\checkmark$ \\
\hline Industry fixed effects & $\checkmark$ & $\checkmark$ & $\checkmark$ & $\checkmark$ \\
\hline Year dummies & $\checkmark$ & $\checkmark$ & $\checkmark$ & $\checkmark$ \\
\hline Observations & 22,642 & 17,580 & 5062 & 22,642 \\
\hline Pseudo- $R^{2}$ & 0.0693 & 0.0696 & 0.1052 & 0.0691 \\
\hline
\end{tabular}

The sample is an unbalanced panel covering 37 Swiss industries between 2008 and 2017. The dependent variable in all columns is the log of occupational employment. All model specifications include fixed effects for occupations, industries and years. Columns (2), (3) and (4) additionally include the implicit emission tax. It is not included in column (1) as otherwise one of the two green potential group dummies are fully absorbed. Data are from the FSO and the SLFS. Standard errors in parentheses are clustered at the industry level. Significance levels for the coefficients are indicated as: ${ }^{*} p<0.1{ }^{* *} p<0.05$; $* * * p<0.01$

explained in Sect. 4.1, but can also be justified empirically. For this purpose, Table 4 again shows the estimations of our previously determined baseline specification. But instead of considering a continuum of green potential, jobs are now divided into two groups with high and low green potential, respectively. ${ }^{11}$

In the first column, we interact the implicit emission tax with the binary green potential dummy. The results show a highly significant positive association between an increase in the implicit emission tax and demand for occupations of the high green potential group. Instead, for the occupation group with low green potential, the association is insignificant. Thus, our previous results based on a continuum of green potential also transfers to a binary case. ${ }^{12}$ In columns (2) and (3), we further analyse whether there exists some within-group heterogeneity. In both cases, the coefficient of the implicit emission

\footnotetext{
${ }^{11}$ Due to reasons of high collinearity between the binary green potential dummy and time varying occupational fixed effects, we stick to the baseline specification.

12 In Table 10 in the "Appendix", we show additional estimations for a binary grouping based on a threshold of 0.45 and 0.55 , which we also use as robustness checks in our subsequent descriptive characterization of the green potential of the Swiss labour market. The results remain stable.
} 
tax interacted with the green potential remains insignificant. For reasons of better comparison, we also show the previous result of the full sample (column 4). Together with the result of column (1), this suggests high betweengroup but not much within-group heterogeneity. This, in turn, empirically supports our subsequent partitioning of occupations into two groups based on their green potential in order to characterize the Swiss labour market.

In summary, our empirical results show that there exists a heterogeneous association between labour demand of occupations with high and low green potential and changes in emission taxes. This supports our initial claim that-when an economy becomes greener-occupations with a high green potential are in relative terms in higher demand than occupations with a low green potential. The result is in line with other work, for example, by Niggli and Rutzer (2020) or Vona et al. (2018). The first study uses a panel dataset of different manufacturing occupations of various European countries to analyse the labour market response to changes in environmental regulations. The latter exploits exogenous variations in environmental regulations among different US labour market regions. Both studies find heterogeneous labour demand responses qualitatively equivalent to this paper.

Having established a heterogeneous association between emission taxes and labour demand of Swiss occupations with high and low green potential, we now take a detailed look at the green potential of the Swiss labour market. This helps us to better understand how well the Swiss labour market is prepared for a transformation towards a green economy.

\section{Characterization of employment in occupations with high green potential}

In the following sections, we will characterize employment in occupations with high green potential along different dimensions. In order to do that, it is necessary to divide occupations into discrete groups. Particularly, we divide the ISCO occupations into two groups based on the estimated green potential of the occupations. For that, we set a threshold at 0.5. Occupations with a green potential equal or above this threshold are considered as occupations with high green potential, the other occupations as occupations with low green potential. The determination of a threshold value is arbitrary to a certain degree. Nevertheless, the chosen value can be justified as follows: First, the choice of the threshold value is empirically supported by the results from Table 4, showing a highly significant positive association between an increase in the implicit emission tax and demand for occupations with a green potential equal to or above 0.5 , whereas the estimated effect for occupations with a green potential below 0.5 is insignificant. Second, the mean green potential (measured by the median) is 0.27 . The threshold value at 0.5 thus indicates that the group of occupations with high green potential includes occupations that have more than one and a half times the median green potential. These are thus occupations with a green potential that is well above average.

\subsection{Size and development}

Given the threshold value of 0.5 , we calculate the number of employees and FTE in occupations with high green potential for Switzerland in the year 2017 of about 739,000 persons and 670,000 FTE. Measured in terms of total employment, the number of people employed and FTE in occupations with high green potential was around $16.7 \%$ and $18.8 \%$, respectively. Figure 1 shows the cumulative employment share (in \%) in dependency of the green potential. If the threshold value is increased (decreased) by 0.05 to 0.55 (0.45), the share of employed persons in the total employed population increases (decreases) to $11 \%(20 \%)$.

As Fig. 2 shows, employment growth in the group of occupations with high green potential was stronger in the time period 2012-2017 than in the group occupations with low green potential: While the number of employees in the group of occupations with high green potential grew by $19.4 \%$ in $2012-2017$, the growth in employment in the group of occupations with low green potential over the same period was only $5.1 \%$. It is worth noting that in absolute terms, growth in the group of occupations with low green potential was significantly higher at 179,363 than in the group of occupations with high green potential at 119,938 .

\subsection{Industry share}

The employment share of occupations with high green potential is distributed differently across industries. In 2017, the highest shares of employees in jobs with high green potential to the total labour force are found for energy, construction, manufacturing and professional, scientific and technical activities (with shares above 20\%) (see Fig. 3). On the other hand, accommodation and food service activities, financial and insurance as well as human health and social work activities have the lowest shares, being well below $10 \%$. 


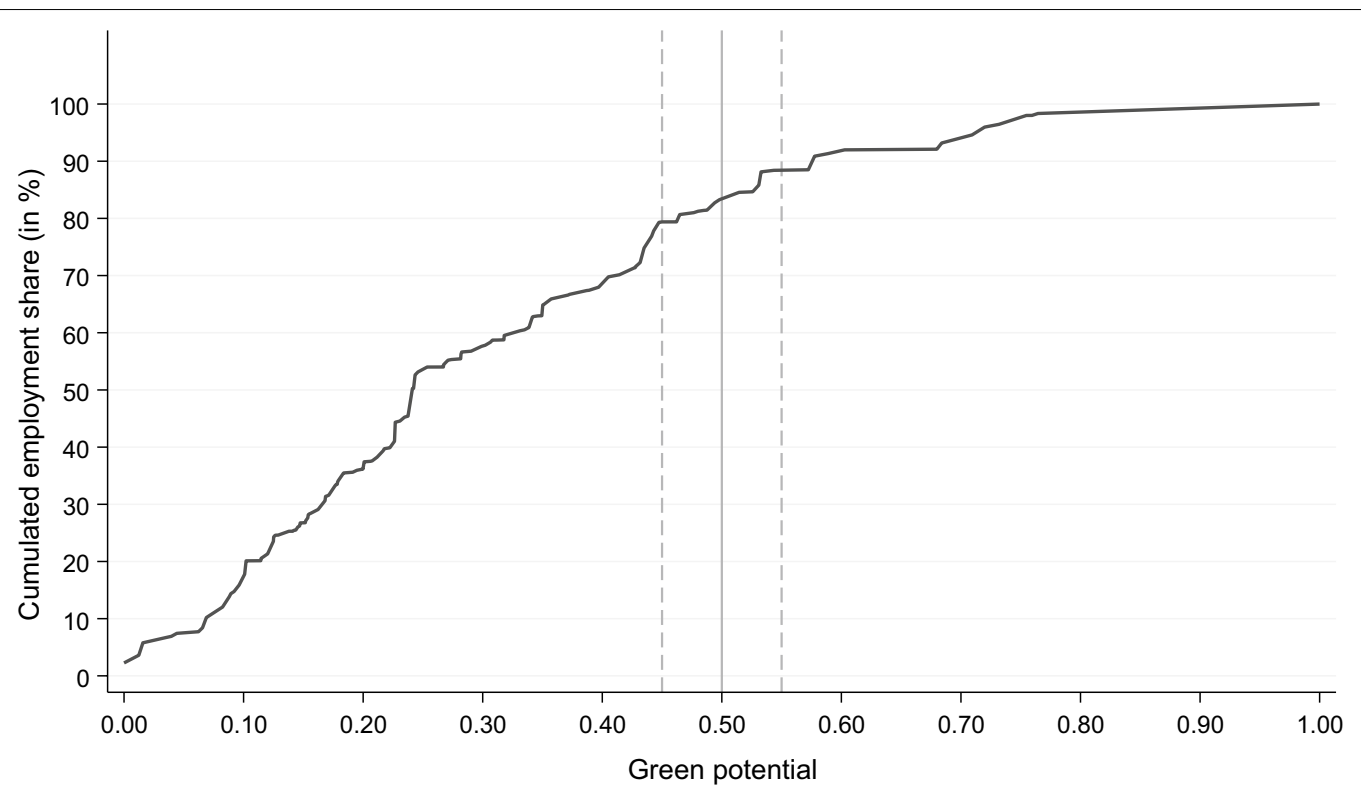

Fig. 1 Cumulated employment share (in \%). Source: Own calculations based on SLFS 2017 (FSO)

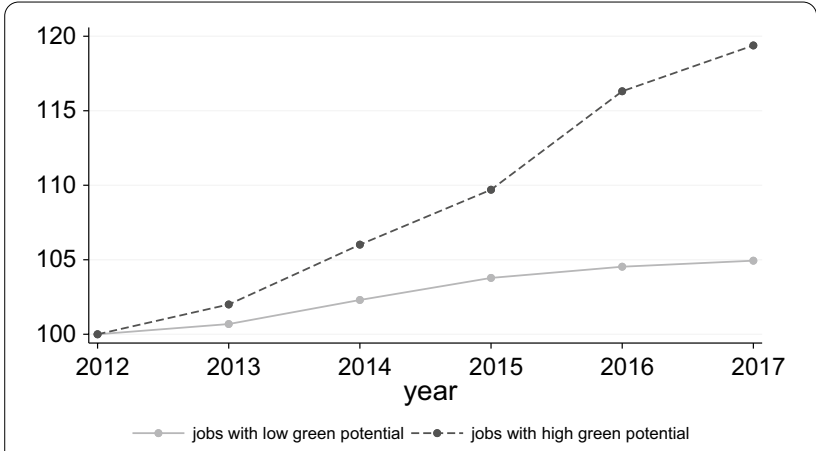

Fig. 2 Employment growth in jobs with low and high green potential, 2012-2017, index: 2012=100. Source: Own calculations based on SLFS (FSO)

For the sake of comparison, Fig. 3 shows the shares of green employment when using the definition of the EGSS, covering employment in industries that produce goods and services contributing to the protection of the environment or the conservation of natural resources. As described in the literature review in Sect. 2, such an industry approach is often used to quantify green employment. Using this definition produces quite different results: Three sectors dominate, namely water supply and waste management, agriculture, forestry and fishing, and construction. In comparison, the shares for three sectors that were still among the four most important sectors (energy, manufacturing, professional, scientific \& technical activities) in terms of green potential are now significantly lower. These differences reveal the impact of the two different approaches. The approach used in this study differs from the EGSS approach in two important aspects: First, it is occupation based and therefore not dependent on the industry to which it belongs. Second, an occupation is classified as one with high green potential if it is associated with skills that are important for the exercise of green tasks; regardless of whether green tasks are already being performed or not and whether the job being carried out already contributes to a green economy or not. What counts is the potential of the occupations to perform green tasks.

\subsection{Socioeconomic characteristics and labour demand indicators}

We have also compared those employed in jobs with high green potential with those employed in jobs with low green potential in terms of age structure, gender, level of education and migratory status ${ }^{13}$ (see Table 5): Employed persons in occupations with high green potential are, on average, younger, more often men, have a higher level of educational attainment and a higher probability of having immigrated than employed persons in occupations with low green potential.

\footnotetext{
${ }^{13}$ We differentiate between employed people that immigrated in the last 10 years (no matter what nationality) and people that have not immigrated or immigrated over 10 years ago.
} 


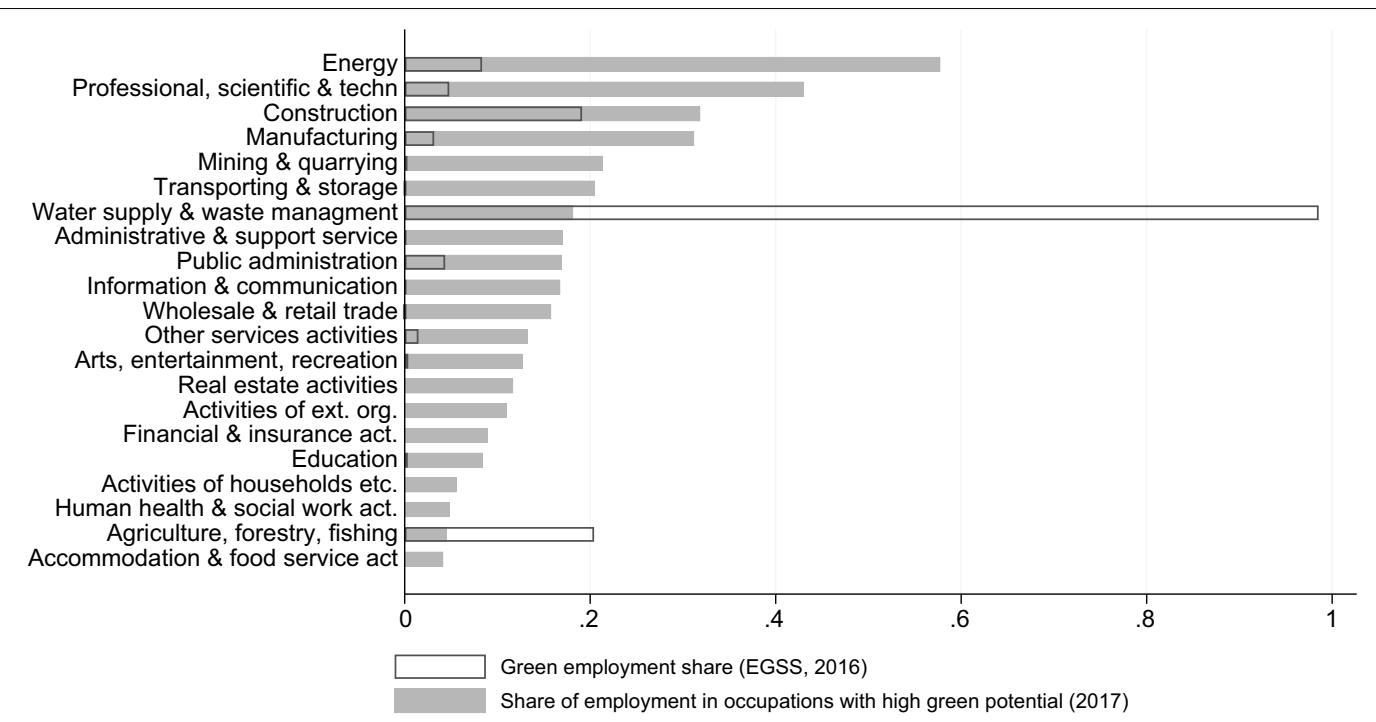

Fig. 3 Employment in jobs with high green potential and green employment as a percentage of total employment by industry. Note: The figure indicates for each industry a the share of employment in occupations with high green potential as a percentage of total employment (measured in FTE) and $\mathbf{b}$ the share of jobs (filled) in industries belonging to the Environmental Goods and Services Sector (EGSS) as a share of the job base (measured in FTE). Source: SLFS 2017 (FSO), EGSS 2016 (FSO)

Table 5 Characterization of jobs with high and low green potential

\begin{tabular}{lll}
\hline Variable & \multicolumn{2}{l}{ Occupations with } \\
\cline { 2 - 3 } & $\begin{array}{l}\text { High green potential } \\
\mathbf{( \% )}\end{array}$ & $\begin{array}{l}\text { Low green } \\
\text { potential } \\
\mathbf{( \% )}\end{array}$ \\
\hline Age & 31.6 & 30.6 \\
$15-34$ & 37.0 & 34.5 \\
$35-49$ & 31.4 & 34.9 \\
$50+$ & & \\
Sex & 76.0 & 48.7 \\
Male & 24.0 & 51.3 \\
Female & & \\
Education & 3.6 & 11.9 \\
Primary & 33.4 & 50.1 \\
Secondary & 63.0 & 38.0 \\
Tertiary & 15.4 & 13.1 \\
Migration rate & 3.6 & 2.9 \\
Rate of job vacancies & 3.6 & 4.6 \\
Rate of unemployment &
\end{tabular}

Own calculations based on $\times 28$ (job vacancies rate) and SLFS 2017 (all other variables). The migration rate is defined as the number of immigrant workers in the labour force (immigrated in the last 10 years) divided by the employed persons. The rate of job vacancies is defined as the number of job vacancies divided by the employed persons plus the number of job vacancies. The rate of unemployment is defined as the number of unemployed persons (as defined by ILO) divided by the economically active persons (that is employed and unemployed persons)
Finally, we have computed two commonly used labour demand indicators, namely the rate of job vacancies and the unemployment rate (see Table 5). ${ }^{14}$ There are differences in both indicators between the two occupational groups. The group of occupations with high green potential shows a higher rate of job vacancies and a lower rate of unemployment compared to the group of occupations with low green potential.

\section{Discussion}

We have estimated the green potential of occupations in Switzerland based on a data-driven methodology that allows quantifying the importance of different skills in performing green tasks. The results show that occupations with a high green potential are predominantly those with an engineering and technical background. We further provide evidence in support of our green potential measure: We have investigated whether we find signs of a heterogeneous demand response in the Swiss labour market due to green economy measures. Specifically, we use changes in the implicit tax rate on greenhouse gas emissions at a twodigit industry level to investigate whether this is associated with a heterogeneous change in the demand for workers with higher green potential relative to those with lower green potential. Our empirical results show a positive association between the demand of occupations with higher

\footnotetext{
${ }^{14}$ The results for the two groups of occupations are computed as a weighted average of the values on the 3-digit level of ISCO occupations, where the number of employees are used as weights.
} 
green potential and an increase in the implicit tax rate on greenhouse gas emissions. In contrast, for occupations with lower green potential, we do not find such an association. This substantiates our measure of green potential. Afterwards, we characterized employment in occupations with high green potential. For that, we divided the ISCO occupations into two groups by applying a particular threshold value. On that basis, we estimate the share of employment in occupations with high green potential to the total labour force to $16.7 \%$ (number of persons employed) and 18.8\% (FTE). Employed persons in occupations with high green potential are, on average, younger, more often men, have a higher level of educational attainment and a higher probability of having immigrated than employed persons in occupations with low green potential. Furthermore, the group of occupations with high green potential has a higher job vacancy rate and a lower unemployment rate compared to the group with low green potential.

At about $20 \%$, a considerable part of the workforce in Switzerland works in occupations with a high green potential and thus presumably also has the corresponding skills. Nevertheless, it can be assumed that a transformation towards a green economy is likely to be accompanied by increased demand for occupations with high green potential, and the availability of suitably trained workers is important for this transformation to take place. How can the relevant skilled workers be provided? Since occupations with high green potential are primarily those with an engineering and technical background, i.e. occupations for which there are already indications of a shortage of skilled workers today, there are already initiatives to increase the number of skilled workers in these fields. ${ }^{15}$ These initiatives address the problem primarily through the recruitment of skilled workers through four approaches: (1) education and training, (2) the utilization of existing skilled labour potential by increasing the level of employment, (3) the retention of existing skilled workers by reducing the migration to other occupations or early career departures, and (4) employment beyond the normal retirement age. Not all of these measures seem equally relevant for occupations with high green potential: As the analyses show, workers in occupations with high green potential have a younger labour force structure than those in other occupations. In this respect, retirements of skilled workers are not as relevant as in other occupations.

\footnotetext{
15 One such initiative is the federal government's initiative for skilled workers (FKI), that aims to improve the development and exploitation of existing domestic skilled labour potentials (Bundesrat, 2018).
}

Furthermore, there is evidence that the labour potential in occupations with high green potential is already being exploited to an above-average extent, leaving little room to increase the level of employment. ${ }^{16}$ For these reasons, the education and training of appropriate professionals seems to be the indicated way to meet an increased future demand due to a development towards a green economy. ${ }^{17}$

Our findings are far from exhaustive. We see three directions for advancing research in this field: The estimation of the green potential of occupations is based on a set of general skills. Building a deeper knowledge about what specific skills (for particular occupations and countries) will be needed for a transformation towards a sustainable economy is a first avenue for future research. A second axis of future research could focus on the development of green tasks within occupations over time. In this context, the approach of Janser (2018) (see Sect. 2 for more details) could be applied to job advertisements in Switzerland. Against the background of a possible increased future demand for occupations with high green potential, research on a third axis could be devoted to the topic of skills mismatches in general and skills shortages in particular, even more so as there is already some evidence of skill shortages for occupations with high green potential.

\section{Appendices}

\section{Appendix 1: Coefficients of the ridge regression} See Table 6

\footnotetext{
16 The exploitation of the labour force potential can be estimated on the basis of the employment rate and the level of employment. It was not possible to calculate the employment rate for the present analysis on the basis of the available data. Since occupations with high green potential are often technical occupations and accordingly trained persons have an above-average employment rate according to other studies (Degen et al., 2016), we assume that this is also the case for occupations with high green potential. Our own analysis based on the SLFS 2017 shows that employed persons in occupations with high green potential have an above-average level of employment (93\% compared to the overall economic value of around $80 \%$ ).
}

17 Another potential option could be international migration. However, since the share of migrants in occupations with high green potential is already above average, the possibilities of covering the (additional) demand for skilled labour through migration already seems to be heavily exploited. 
Table 6 List of the coefficients of the ridge regression

\section{General skill from O*NET}

Achievement

Active learning

Active listening

$-0.03$

Administration and management

Analyzing data or information

0.04

Assisting and caring for others

Biology

Building and construction

Chemistry

Clerical

Coaching and developing others

Communicating with persons outside organization

Communicating with supervisors peers or subordinates

Communications and media

Complex problem solving

Computers and electronics

Controlling machines and processes

$-0.07$

Coordinating the work and activities of others

Coordination

Critical thinking

Customer and personal service

Design

Developing and building teams

Developing objectives and strategies

0.01

Documenting recording information

Economics and accounting

Education and training

Engineering and technology

English language

Equipment maintenance

0.02

Equipment selection

$-0.03$

Establishing and maintaining interpersonal relationships

$-0.02$

Estimating the quantifiable characteristics of products events or information

0.02

Evaluating information to determine compliance with standards

0.04

Fine arts

$-0.09$

Food production

$-0.03$

Foreign language

$-0.08$

Geography

Handling and moving objects

$-0.04$

History and archeology

Identifying objects actions and events

$-0.02$

$-0.05$

Independence

$-0.03$

Inspecting equipment structures or material

0.01

Installation

0.05

Instructing

Interacting with computers

0.01

Interpreting the meaning of information for others

0.02

Judging the qualities of things services or people 
Table 6 (continued)

\section{General skill from O*NET}

Ridge coefficient

Law and government

Learning Strategies

Making Decisions and Solving Problems

$-0.04$

Management of Financial Resources

0.05

Management of Material Resources

0.03

Management of Personnel Resources

0.01

Mathematics

0.01

Mechanical

0.05

Medicine and Dentistry

Monitor Processes Materials or Surroundings

Monitoring

Monitoring and Controlling Resources

Negotiation

Operating Vehicles Mechanized Devices or Equipment

Operation and Control

Operation Monitoring

Operations Analysis

Organizing Planning and Prioritizing Work

Performing Administrative Activities

Personnel and Human Resources

Persuasion

Philosophy and Theology

Physics

Production and Processing

Psychology

Public Safety and Security

Quality Control Analysis

Reading Comprehension

Recognition

Relationships

Repairing

Repairing and Maintaining Electronic Equipment

Repairing and Maintaining Mechanical Equipment

Science

Selling or Influencing Others

Social Perceptiveness

Sociology and Anthropology

Speaking

Support

$-0.13$

Systems Analysis

Systems Evaluation

0.05

Technology Design

$-0.01$

Telecommunications 
Table 6 (continued)

\section{General skill from O*NET}

Ridge coefficient

Therapy and Counseling

Thinking Creatively

$-0.02$

Time Management

$-0.03$

Training and Teaching Others

$-0.03$

Transportation

0.01

Troubleshooting

0.02

Updating and Using Relevant Knowledge

$-0.01$

Working Conditions

0.05

Writing

0.04

\section{Appendix 2: Green potential of ISCO occupations}

\section{See Table 7}

Table 7 List of ISCO occupations and their predicted green potential

\begin{tabular}{|c|c|c|}
\hline ISCO & Job title & $\begin{array}{l}\text { Predicted } \\
\text { greenness }\end{array}$ \\
\hline 214 & Engineering professionals (excluding electrotechnology) & 1.00 \\
\hline 211 & Physical and earth science professionals & 0.76 \\
\hline 131 & Production managers in agriculture, forestry and fisheries & 0.76 \\
\hline 210 & Science and engineering professionals, nos & 0.75 \\
\hline 312 & Mining, manufacturing and construction supervisors & 0.75 \\
\hline 215 & Electrotechnology engineers & 0.73 \\
\hline 132 & Manufacturing, mining, construction, and distribution managers & 0.72 \\
\hline 216 & Architects, planners, surveyors and designers & 0.71 \\
\hline 112 & Managing directors and chief executives & 0.68 \\
\hline 314 & Life science technicians and related associate professionals & 0.68 \\
\hline 110 & Chief executives, senior officials and legislators, nos & 0.65 \\
\hline 111 & Legislators and senior officials & 0.60 \\
\hline 213 & Life science professionals & 0.59 \\
\hline 311 & Physical and engineering science technicians & 0.58 \\
\hline 142 & Retail and wholesale trade managers & 0.57 \\
\hline 130 & Production and specialized services managers, nos & 0.54 \\
\hline 242 & Administration professionals & 0.53 \\
\hline 100 & Managers, nos & 0.53 \\
\hline 143 & Other services managers & 0.53 \\
\hline 741 & Electrical equipment installers and repairers & 0.51 \\
\hline 740 & Electrical and electronic trades workers, nos & 0.50 \\
\hline 310 & Science and engineering associate professionals, nos & 0.50 \\
\hline 122 & Sales, marketing and development managers & 0.49 \\
\hline 212 & Mathematicians, actuaries and statisticians & 0.49 \\
\hline 313 & Process control technicians & 0.49 \\
\hline 120 & Administrative and commercial managers, nos & 0.48 \\
\hline 742 & Electronics and telecommunications installers and repairers & 0.48 \\
\hline 754 & Other craft and related workers & 0.48 \\
\hline
\end{tabular}


Table 7 (continued)

\begin{tabular}{|c|c|c|}
\hline ISCO & Job title & $\begin{array}{l}\text { Predicted } \\
\text { greenness }\end{array}$ \\
\hline 723 & Machinery mechanics and repairers & 0.46 \\
\hline 140 & Hospitality, retail and other services managers, nos & 0.46 \\
\hline 710 & Building and related trades workers, excluding electricians, nos & 0.45 \\
\hline 711 & Building frame and related trades workers & 0.45 \\
\hline 333 & Business services agents & 0.44 \\
\hline 731 & Handicraft workers & 0.44 \\
\hline 712 & Building finishers and related trades workers & 0.44 \\
\hline 332 & Sales and purchasing agents and brokers & 0.43 \\
\hline 133 & Information and communications technology service managers & 0.43 \\
\hline 622 & Fishery workers, hunters and trappers & 0.43 \\
\hline 240 & Business and administration professionals, nos & 0.43 \\
\hline 612 & Animal producers & 0.43 \\
\hline 121 & Business services and administration managers & 0.43 \\
\hline 931 & Mining and construction labourers & 0.41 \\
\hline 620 & Market-oriented skilled forestry, fishery and hunting workers, nos & 0.41 \\
\hline 251 & Software and applications developers and analysts & 0.41 \\
\hline 343 & Artistic, cultural and culinary associate professionals & 0.40 \\
\hline 811 & Mining and mineral processing plant operators & 0.39 \\
\hline 720 & Metal, machinery and related trades workers, nos & 0.39 \\
\hline 610 & Market-oriented skilled agricultural workers, nos & 0.39 \\
\hline 200 & Professionals, nos & 0.37 \\
\hline 250 & Information and communications technology professionals, nos & 0.37 \\
\hline 600 & Skilled agricultural, forestry and fishery workers, nos & 0.36 \\
\hline 243 & Sales, marketing and public relations professionals & 0.36 \\
\hline 813 & Chemical and photographic products plant and machine operators & 0.35 \\
\hline 613 & Mixed crop and animal producers & 0.35 \\
\hline 700 & Craft and related trades workers, nos & 0.35 \\
\hline 252 & Database and network professionals & 0.35 \\
\hline 621 & Forestry and related workers & 0.34 \\
\hline 241 & Finance professionals & 0.34 \\
\hline 721 & Sheet and structural metal workers, moulders and welders, and related workers & 0.34 \\
\hline 315 & Ship and aircraft controllers and technicians & 0.33 \\
\hline 611 & Market gardeners and crop growers & 0.33 \\
\hline 634 & Subsistence fishers, hunters, trappers and gatherers & 0.33 \\
\hline 713 & Painters, building structure cleaners and related trades workers & 0.32 \\
\hline 300 & Technicians and associate professionals, nos & 0.32 \\
\hline 835 & Ships' deck crews and related workers & 0.31 \\
\hline 722 & Blacksmiths, toolmakers and related trades workers & 0.31 \\
\hline 752 & Wood treaters, cabinet-makers and related trades workers & 0.31 \\
\hline 352 & Telecommunications and broadcasting technicians & 0.30 \\
\hline 134 & Professional services managers & 0.30 \\
\hline 933 & Transport and storage labourers & 0.29 \\
\hline 350 & Information and communications technicians, nos & 0.29 \\
\hline 232 & Vocational education teachers & 0.28 \\
\hline 141 & Hotel and restaurant managers & 0.28 \\
\hline 330 & Business and administration associate professionals, nos & 0.28 \\
\hline 225 & Veterinarians & 0.27 \\
\hline 730 & Handicraft and printing workers, nos & 0.27 \\
\hline 961 & Refuse workers & 0.27 \\
\hline
\end{tabular}


Table 7 (continued)

\begin{tabular}{|c|c|c|}
\hline ISCO & Job title & $\begin{array}{l}\text { Predicted } \\
\text { greenness }\end{array}$ \\
\hline 821 & Assemblers & 0.27 \\
\hline 351 & Information and communications technology operations and user support technicians & 0.27 \\
\hline 834 & Mobile plant operators & 0.27 \\
\hline 930 & Labourers in mining, construction, manufacturing and transport, nos & 0.27 \\
\hline 261 & Legal professionals & 0.25 \\
\hline 335 & Regulatory government associate professionals & 0.25 \\
\hline 820 & Assemblers, nos & 0.24 \\
\hline 331 & Financial and mathematical associate professionals & 0.24 \\
\hline 750 & Food processing, wood working, garment and other craft and related trades workers, nos & 0.24 \\
\hline 522 & Shop salespersons & 0.24 \\
\hline 262 & Librarians, archivists and curators & 0.24 \\
\hline 231 & University and higher education teachers & 0.23 \\
\hline 632 & Subsistence livestock farmers & 0.23 \\
\hline 830 & Drivers and mobile plant operators, nos & 0.23 \\
\hline 411 & General office clerks & 0.23 \\
\hline 630 & Subsistence farmers, fishers, hunters and gatherers, nos & 0.23 \\
\hline 800 & Plant and machine operators and assemblers, nos & 0.23 \\
\hline 221 & Medical doctors & 0.23 \\
\hline 810 & Stationary plant and machine operators, nos & 0.22 \\
\hline 921 & Agricultural, forestry and fishery labourers & 0.22 \\
\hline 833 & Heavy truck and bus drivers & 0.22 \\
\hline 751 & Food processing and related trades workers & 0.21 \\
\hline 950 & Street and related sales and service workers, nos & 0.21 \\
\hline 951 & Street and related service workers & 0.21 \\
\hline 952 & Street vendors (excluding food) & 0.21 \\
\hline 521 & Street and market salespersons & 0.21 \\
\hline 960 & Refuse workers and other elementary workers, nos & 0.21 \\
\hline 900 & Elementary occupations, nos & 0.21 \\
\hline 340 & Legal, social, cultural and related associate professionals, nos & 0.20 \\
\hline 520 & Sales workers, nos & 0.20 \\
\hline 541 & Protective services workers & 0.20 \\
\hline 814 & Rubber, plastic and paper products machine operators & 0.20 \\
\hline 220 & Health professionals, nos & 0.20 \\
\hline 223 & Traditional and complementary medicine professionals & 0.20 \\
\hline 260 & Legal, social and cultural professionals, nos & 0.19 \\
\hline 732 & Printing trades workers & 0.19 \\
\hline 633 & Subsistence mixed crop and livestock farmers & 0.19 \\
\hline 812 & Metal processing and finishing plant operators & 0.19 \\
\hline 226 & Other health professionals & 0.18 \\
\hline 816 & Food and related products machine operators & 0.18 \\
\hline 832 & Car, van and motorcycle drivers & 0.18 \\
\hline 524 & Other sales workers & 0.18 \\
\hline 818 & Other stationary plant and machine operators & 0.18 \\
\hline 513 & Waiters and bartenders & 0.18 \\
\hline 430 & Numerical and material recording clerks, nos & 0.17 \\
\hline 831 & Locomotive engine drivers and related workers & 0.17 \\
\hline 514 & Hairdressers, beauticians and related workers & 0.17 \\
\hline 512 & Cooks & 0.17 \\
\hline
\end{tabular}


Table 7 (continued)

\begin{tabular}{|c|c|c|}
\hline ISCO & Job title & $\begin{array}{l}\text { Predicted } \\
\text { greenness }\end{array}$ \\
\hline 500 & Service and sales workers, nos & 0.17 \\
\hline 432 & Material-recording and transport clerks & 0.16 \\
\hline 941 & Food preparation assistants & 0.16 \\
\hline 815 & Textile, fur and leather products machine operators & 0.16 \\
\hline 631 & Subsistence crop farmers & 0.15 \\
\hline 932 & Manufacturing labourers & 0.15 \\
\hline 265 & Creative and performing artists & 0.15 \\
\hline 753 & Garment and related trades workers & 0.15 \\
\hline 817 & Wood processing and papermaking plant operators & 0.15 \\
\hline 342 & Sports and fitness workers & 0.15 \\
\hline 222 & Nursing and midwifery professionals & 0.15 \\
\hline 431 & Numerical clerks & 0.15 \\
\hline 912 & Vehicle, window, laundry and other hand cleaning workers & 0.14 \\
\hline 510 & Personal service workers, nos & 0.14 \\
\hline 910 & Cleaners and helpers, nos & 0.14 \\
\hline 224 & Paramedical practitioners & 0.14 \\
\hline 264 & Authors, journalists and linguists & 0.14 \\
\hline 320 & Health associate professionals, nos & 0.13 \\
\hline 324 & Veterinary technicians and assistants & 0.13 \\
\hline 230 & Teaching professionals, nos & 0.13 \\
\hline 321 & Medical and pharmaceutical technicians & 0.13 \\
\hline 233 & Secondary education teachers & 0.12 \\
\hline 235 & Other teaching professionals & 0.12 \\
\hline 516 & Other personal services workers & 0.12 \\
\hline 511 & Travel attendants, conductors and guides & 0.11 \\
\hline 400 & Clerical support workers, nos & 0.11 \\
\hline 323 & Traditional and complementary medicine associate professionals & 0.11 \\
\hline 410 & General and keyboard clerks, nos & 0.10 \\
\hline 911 & Domestic, hotel and office cleaners and helpers & 0.10 \\
\hline 515 & Building and housekeeping supervisors & 0.10 \\
\hline 325 & Other health associate professionals & 0.10 \\
\hline 523 & Cashiers and ticket clerks & 0.09 \\
\hline 441 & Other clerical support workers & 0.09 \\
\hline 263 & Social and religious professionals & 0.09 \\
\hline 234 & Primary school and early childhood teachers & 0.08 \\
\hline 420 & Customer services clerks, nos & 0.08 \\
\hline 412 & Secretaries (general) & 0.07 \\
\hline 422 & Client information workers & 0.07 \\
\hline 413 & Keyboard operators & 0.06 \\
\hline 962 & Other elementary workers & 0.06 \\
\hline 531 & Child care workers and teachers' aides & 0.04 \\
\hline 421 & Tellers, money collectors and related clerks & 0.04 \\
\hline 341 & Legal, social and religious associate professionals & 0.04 \\
\hline 530 & Personal care workers, nos & 0.02 \\
\hline 322 & Nursing and midwifery associate professionals & 0.02 \\
\hline 334 & Administrative and specialized secretaries & 0.01 \\
\hline 532 & Personal care workers in health services & 0.00 \\
\hline
\end{tabular}




\section{Appendix 3: Industries used in the empirical analysis}

\begin{tabular}{|c|c|c|}
\hline Industry & Observations & $\overline{\tau_{2017} / \tau_{2008}}$ \\
\hline D10-T12 & 1028 & 0.91 \\
\hline D13-T15 & 1550 & 1.07 \\
\hline D16-T18 & 972 & 0.92 \\
\hline D19-T20 & 873 & 0.99 \\
\hline D21 & 881 & 1.06 \\
\hline D22-T23 & 1140 & 0.77 \\
\hline D24-T25 & 1579 & 0.71 \\
\hline D26 & 1018 & 1.40 \\
\hline $\mathrm{D} 27$ & 749 & 1.30 \\
\hline D28 & 1221 & 1.16 \\
\hline D29-T30 & 1054 & 1.19 \\
\hline D31-T33 & 1548 & 0.96 \\
\hline D35 & 705 & 2.13 \\
\hline D36-T39 & 781 & 1.89 \\
\hline D41-T43 & 777 & 2.00 \\
\hline D45 & 1251 & 0.58 \\
\hline D46 & 985 & 0.77 \\
\hline D47 & 911 & 0.69 \\
\hline D49-T51 & 1903 & 0.60 \\
\hline D52 & 1721 & 0.60 \\
\hline D53 & 252 & 0.60 \\
\hline D55-T56 & 1563 & 0.23 \\
\hline D58-T60 & 1062 & 0.47 \\
\hline D61 & 390 & 0.22 \\
\hline D62-T63 & 1083 & 0.63 \\
\hline D64 & 1128 & 0.06 \\
\hline D65 & 1088 & 0.64 \\
\hline D68 & 350 & 1.03 \\
\hline D69-T70 & 1483 & 0.94 \\
\hline D71 & 738 & 0.94 \\
\hline D72 & 886 & 1.11 \\
\hline D73-T75 & 2065 & 0.40 \\
\hline D77-T82 & 2069 & 0.60 \\
\hline D85 & 2175 & 0.69 \\
\hline D87-T88 & 944 & 0.64 \\
\hline D90-T93 & 2033 & 2.13 \\
\hline D94-T96 & 1436 & 1.11 \\
\hline
\end{tabular}

The first column shows the Noga nomenclature. The second column states the number of distinct ISCO occupations per year and industry. The third column shows the incremental change in the industry's implicit tax rate between 2017 and 2008. A value less than one means that the implicit tax rate has decreased, a value larger than one that it has increased

\section{Appendix 4: Robustness checks}

See Tables 8, 9 and 10.

Table 8 Association between Implicit Emission Tax and Employment: Varying considered occupations

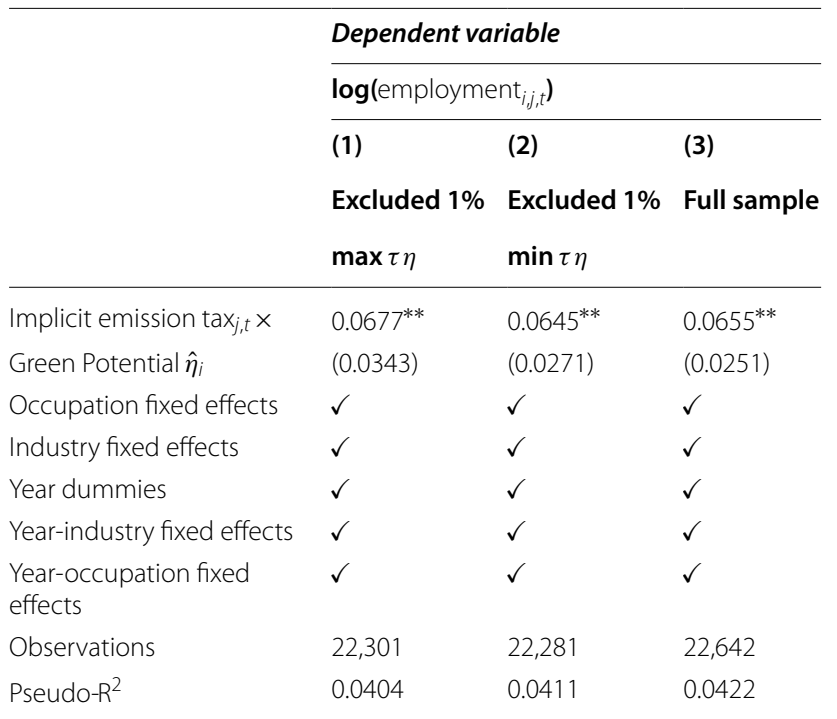

The sample is an unbalanced panel covering 37 Swiss industries between 2008 and 2017. The dependent variable in all columns is the log of occupational employment. All model specifications include fixed effects for occupations, industries and years. In addition, yearly industry and occupation fixed effects are considered. Column (1) excludes the $1 \%$ of observations having the largest value of the variable of interest implicit emission tax interacted with the green potential and column (2) the $1 \%$ with the lowest value. Column (3) shows the full sample for comparison. Data are from the FSO and the SLFS. Standard errors in parentheses are clustered at the industry level. Significance levels for the coefficients are indicated as: ${ }^{*} p<0.1 ;{ }^{* *} p<0.05$; $^{* * *} p<0.01$ 
Table 9 Association between implicit emission tax and employment: varying time span and industries

\begin{tabular}{|c|c|c|c|c|}
\hline & \multicolumn{4}{|c|}{ Dependent variable } \\
\hline & \multicolumn{4}{|c|}{$\log \left(\right.$ employment $\left.t_{i, t}\right)$} \\
\hline & $(1)$ & (2) & (3) & (4) \\
\hline & $2008-$ & 2013- & 15 industries & 15 industries \\
\hline & 2012 & 2017 & Highest $\Delta \tau_{2008-2017}$ & Lowest $\Delta \tau_{2008-2017}$ \\
\hline Implicit emission $\operatorname{tax}_{j, t} \times$ & $0.0668^{* * *}$ & $0.0645^{* *}$ & $0.0927^{* * *}$ & 0.0586 \\
\hline Green potential $\hat{\eta}_{i}$ & $(0.0254)$ & $(0.0259)$ & $(0.0360)$ & $(0.0544)$ \\
\hline Occupation fixed effects & $\checkmark$ & $\checkmark$ & $\checkmark$ & $\checkmark$ \\
\hline Industry fixed effects & $\checkmark$ & $\checkmark$ & $\checkmark$ & $\checkmark$ \\
\hline Year dummies & $\checkmark$ & $\checkmark$ & $\checkmark$ & $\checkmark$ \\
\hline Year-industry fixed effects & $\checkmark$ & $\checkmark$ & $\checkmark$ & $\checkmark$ \\
\hline Year-occupation fixed effects & $\checkmark$ & $\checkmark$ & $\checkmark$ & $\checkmark$ \\
\hline Observations & 11,059 & 11,583 & 7616 & 7926 \\
\hline Pseudo-R ${ }^{2}$ & 0.0377 & 0.0378 & 0.0196 & 0.0044 \\
\hline
\end{tabular}

The dependent variable in all columns is the log of occupational employment. All model specifications include fixed effects for occupations, industries and years. In addition, yearly industry and occupation fixed effects are considered. Column (1) shows an unbalanced panel covering 37 Swiss industries between 2008 and 2012 and column (2) between 2013 and 2017. Column (3) contains a subset of the 15 industries exhibiting the largest incremental increase in the implicit tax rate between 2008 and 2017 and column (4) a subset of the 15 industries with the lowest incremental increase between 2008 and 2017. Data are from the FSO and the SLFS. Standard errors in parentheses are clustered at the industry level. Significance levels for the coefficients are indicated as: ${ }^{*} p<0.1 ;{ }^{* *} p<0.05$; ${ }^{* * *} p<0.01$

Table 10 Association between implicit emission tax and employment: alternative binary cases

\begin{tabular}{|c|c|c|c|}
\hline & \multicolumn{3}{|c|}{ Dependent variable } \\
\hline & \multicolumn{3}{|c|}{ log(employment $\left.t_{i, t, t}\right)$} \\
\hline & (1) & $(2)$ & (3) \\
\hline & $x=0.5$ & $x=0.45$ & $x=0.55$ \\
\hline \multirow{2}{*}{ Implicit emission tax $\operatorname{tax}_{j, t} \times \nVdash_{\eta \geq x}$} & $0.0381^{* * *}$ & $0.0343^{* * *}$ & $0.0419^{* * *}$ \\
\hline & $(0.0147)$ & $(0.0140)$ & $(0.0105)$ \\
\hline \multirow{2}{*}{ Implicit emission $\operatorname{tax}_{j, t} \times \nVdash_{\eta<x}$} & 0.0071 & 0.0050 & 0.0080 \\
\hline & $(0.0106)$ & $(0.0105)$ & $(0.0154)$ \\
\hline Occupation fixed effects & $\checkmark$ & $\checkmark$ & $\checkmark$ \\
\hline Industry fixed effects & $\checkmark$ & $\checkmark$ & $\checkmark$ \\
\hline Year dummies & $\checkmark$ & $\checkmark$ & $\checkmark$ \\
\hline Observations & 22,642 & 22,642 & 22,642 \\
\hline Pseudo-R ${ }^{2}$ & 0.0693 & 0.0694 & 0.0692 \\
\hline
\end{tabular}

The sample is an unbalanced panel covering 37 Swiss industries between 2008 and 2017. The dependent variable in all columns is the log of occupational employment. All model specifications include fixed effects for occupations, industries and years. The implicit emission tax is not included as otherwise one of the two green potential group dummies are fully absorbed. Data are from the FSO and the SLFS. Standard errors in parentheses are clustered at the industry level. Significance levels for the coefficients are indicated as: ${ }^{*} p<0.1$; ${ }^{* *} p<0.05 ;{ }^{* * *} p<0.01$

\section{Abbreviations}

SLFS: Swiss labour force survey; SOC: Standard occupational classification system; ISCO: International standard classification of occupations; FTE: Full-time equivalents; EGSS: Environmental goods and services sector.

\section{Acknowledgements}

We are grateful to Rolf Weder, Matthias Niggli, Wolfram Kägi and Christopher Huddleston for comments and suggestions. Comments from two anonymous reviewers and the editor contributed significantly to sharpening the content of the paper. All errors remain our own responsibility.

\section{Author contributions}

$M L$ carried out the descriptive analyses to describe the green potential in Switzerland. He was also responsible for the writing of the texts. CR performed the estimation of the green potential using data from O*NET and conducted the regressions. All authors read and approved the final manuscript.

\section{Funding}

This work has been supported by the Swiss National Science Foundation (SNSF) within the framework of the National Research Program Sustainable Economy: resource-friendly, future-oriented, innovative (NRP 73), Grant-No 407340-172430

\section{Availability of data and materials}

Data from O*NET (U.S. Department of Labor, Employment and Training Administration ) can be accessed via https://www.onetcenter.org/db_relea ses.html. Data from the SLFS was made available by the OFS after signing a data usage contract. The data can be requested from the OFS by stating the purpose of use. 


\section{Declarations}

\section{Competing interests}

The authors declare that they have no competing interests.

\section{Author details}

'BSS Economic Consultants, Aeschengraben 9, 4051 Basel, Switzerland. ${ }^{2}$ Faculty of Business and Economics, University of Basel, Peter Merian-Weg 6, 4052 Basel, Switzerland.

Received: 30 November 2020 Accepted: 1 October 2021 Published online: 30 October 2021

\section{References}

Acemoglu, D., \& Autor, D. (2011). Skills, tasks and technologies: Implications for employment and earnings. In Handbook of labor economics (Vol. 4, pp. 1043-1171). Elsevier.

BAFU. (2016). Bericht an den bundesrat, grüne wirtschaft: Massnahmen des bundes für eine ressourcenschonende, zukunfstfähige schweiz. Bern. Retrieved from https://www.bafu.admin.ch/bafu/de/home/themen/wirts chaft-konsum/fachinformationen/massnahmen-des-bundes-fuer-resso urcenschonung.html.

BAFU. (2016). Bericht an den bundesrat, grüne wirtschaft: Massnahmen des bundes für eine ressourcenschonende, zukunfstfähige schweiz. Bern. Retrieved from https://www.bafu.admin.ch/bafu/de/home/themen/ wirtschaft-konsum/fachinformationen/massnahmen-des bundes-fuerressourcenschonung.html.

Bowen, A., Kuralbayeva, K., \& Tipoe, E. L. (2018). Characterising green employment: The impacts of 'greening' on workforce composition. Energy Economics, 72, 263-275.

Bundesrat. (2016). Strategie nachhaltige entwicklung 2016-2019. Retrieved from https://www.are.admin.ch/are/de/home/nachhaltige-entwi cklung.html.

Bundesrat. (2018). Schlussbericht zur fachkräfteinitative. Retrieved from https://www.seco.admin.ch/seco/de/home/Arbeit/Fachkraefteinit iative.html.

Consoli, D., Marin, G., Marzucchi, A., \& Vona, F. (2016). Do green jobs differ from non-green jobs in terms of skills and human capital? Research Policy, 45(5), 1046-1060.

Degen, K., Ragni, T., Bieri, D., \& Marti, S. (2016). Fachkräftemangel in der schweiz: Indikatorensystem zur beurteilung der fachkräftenachfragel. Bern: Staatssekretariat für Wirtschaft SECO. Retrieved from https:// www.seco.admin.ch/seco/de/home/wirtschaftslage---wirtschaftspoli tik/wirtschaftspolitik arbeitsmarkt/fachkraefteinitiative.html
Dierdorff, E. C., Norton, J. J., Drewes, D. W., Kroustalis, C. M., Rivkin, D., \& Lewis, P. (2009). Greening of the world of work: Implications for $\mathrm{O}^{*}$ netsoc and new and emerging occupations. The National Center for O*NET Development.

Esposito, M., Haider, A., Samaan, D., \& Semmler, W. (2017). Enhancing job creation through green transformation. In T. Altenburg \& C. Assmann (Eds.), Green industrial policy: Concept, policies, country experiences (pp. 51-67). Geneva and Bonn: UN Environment and German Development Institute/ Deutsches Institut für Entwicklungspolitik).

Eurostat. (2016). Environmental goods and services sector accounts—Practical guide-2016 edition [Computer software manual]. Retrieved from https://ec.europa.eu/eurostat/web/products-manuals-and-guidelines/-/ KS-GQ-16-011. https://doi.org/10.2785/688181.

ILO. (2018). Greening with jobs_-World employment and social outlook 2018. International Labour Office. Retrieved from https://www.ilo.org/global/ research/global-reports/weso/greening-with-jobs/lang--en/index.htm.

Janser, M. (2018). The greening of jobs in germany: First evidence from a text mining based index and employment register data (Tech. Rep.). IABDiscussion Paper.

Marin, G., \& Vona, F. (2019). Climate policies and skill-biased employment dynamics: Evidence from eu countries. Journal of Environmental Economics and Management, 98, 102253.

Martinez-Fernandez, C., Hinojosa, C., \& Miranda, G. (2010). Green jobs and skills: The local labour market implications of addressing climate change. Working document, CFE/LEED, OECD. Retrieved from www.oecd.org/datao ecd/54/43/44683169.pdf?contentld $=44683170$.

Niggli, M., \& Rutzer, C. (2020). Environmental Policy and Heterogeneous Labor Market Effects: Evidence from Europe (Working paper No. 2020/09). Faculty of Business and Economics-University of Basel. Retrieved from https://ideas.repec.org/p/bsl/wpaper/2020-09.html.

OECD. (2017). Getting skills right: Skills for jobs indicators. OECD Publishing, Paris. Retrieved from https://doi.org/10.1787/9789264277878-en.

Rutzer, C., Niggli, M., \& Weder, R. (2020). Estimating the Green Potential of Occupations: A New Approach Applied to the U.S. Labor Market (Working paper No. 2020/03). Faculty of Business and Economics_-University of Basel. https://ideas.repec.org/p/bsl/wpaper/2020-03.html.

Strietska-Ilina, O., Hofmann, C., Haro, M. D., \& Jeon, S. (2011). Skills for green jobs: A global view. synthesis report based on 21 country studies. International Labour Office, Skills and Employability Department, Job Creation and Enterprise Development Department - Geneva: ILO.

Vona, F., Marin, G., Consoli, D., \& Popp, D. (2018). Environmental regulation and green skills: An empirical exploration. Journal of the Association of Environmental and Resource Economists, 5(4), 713-753.

\section{Submit your manuscript to a SpringerOpen ${ }^{\odot}$ journal and benefit from:}

- Convenient online submission

- Rigorous peer review

- Open access: articles freely available online

- High visibility within the field

- Retaining the copyright to your article

Submit your next manuscript at $\boldsymbol{\nabla}$ springeropen.com 